\title{
FOREST STRUCTURE RETRIEVAL FROM ECOSAR P-BAND SINGLE-PASS INTERFEROMETRY
}

\author{
Batuhan Osmanoglu ${ }^{1}$, Rafael Rincon ${ }^{l}$, SeungKuk Lee ${ }^{l}$, Temilola Fatoyinbo ${ }^{1}$, Tobias Bollian ${ }^{1,2}$ \\ 1 NASA Goddard Space Flight Center, Greenbelt, MD \\ 2 Universities Space Research Association, Columbia, MD
}

\begin{abstract}
EcoSAR is a single-pass (dual antenna) digital beamforming, P-band radar system that is designed for remote sensing of dense forest structure. Forest structure retrievals require the measurement related to the vertical dimension, for which several techniques have been developed over the years. These techniques use polarimetric and interferometric aspects of the SAR data, which can be collected using EcoSAR. In this paper we describe EcoSAR system in light of its interferometric capabilities and investigate forest structure retrieval techniques.
\end{abstract}

\section{Index Terms- Interferometry, SAR, Digital Beamforming}

\section{INTRODUCTION}

Forest biomass is an important part of the global carbon budget and it is hard to measure using remote sensing techniques due to its three-dimensional structure. Forests are presumed to contain over $80 \%$ of the terrestrial biomass. Foliar biomass typically covers less than $10 \%$ of the total aboveground biomass [1]. For decades radar backscatter observed in different polarizations and frequencies were used to estimate biomass $[\mathrm{REF}]$, however with the increase in polarimetric SAR data availability, polarimetric interferometry techniques are gaining popularity [REF].

In this paper we present NASA Goddard's EcoSAR system characteristics, investigate its applicability for remote sensing of forest structure, and discuss the potential techniques.

\section{ECOSAR}

EcoSAR is a dual antenna, wideband (up to $200 \mathrm{MHz}$ ) Synthetic Aperture Radar (SAR) system operating at 435 $\mathrm{MHz}$ that employs a wideband digital beamforming architecture for the measurement of science parameters (Figure 1). EcoSAR is a quad-pol system with 32 independent antenna sub arrays (eight active sub arrays for each polarization)[2], [3]. During the first EcoSAR flight campaign in 2014, data was collected in wide-beam imaging mode, with a single sub-array transmitting. This mode allows for imaging multiple ground swaths on both sides of the airplane[4].

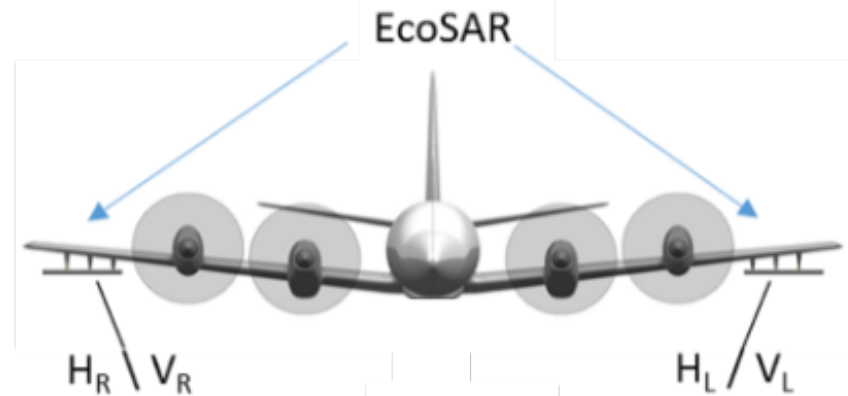

Figure 1 EcoSAR's dual antenna configuration. The antenna separation is $25 \mathrm{~m}$ and both antennas are dual polarimetric capable of horizontal $(\mathrm{H})$ and vertical $(\mathrm{V})$ transmit and receive). Subscript ${ }_{R}$ and ${ }_{L}$ indicate right and left antennas.

\section{MEASUREMENTS}

EcoSAR measures intensity and phase of the target area in co-pol $(\mathrm{HH}, \mathrm{VV})$ and cross-pol $(\mathrm{HV}, \mathrm{VH})$ signals. Intensity measurements have long been used for forest biomass estimations with most success in cross-pol data. [1], [5], [6]. Modeling based approaches take these estimates one step further, and allow for combination of multiple polarization data [7]. In addition to polarimetric backscatter, interferometric phase center height is shown to improve above ground biomass (AGB) estimates significantly [8]. Finally Polarimetric SAR Interferometry (PolInSAR) is shown to estimate forest height accurately based on random volume over ground techniques [9], [10]. EcoSAR produces data that can be used with all of these methods mentioned above.

\subsection{Polarimetric Backscatter (SAR)}

\subsection{Phase center height (InSAR)}

\subsection{Random Volume over Ground (PolInSAR)}

\section{MEASUREMENT EXAMPLES}

4.1. Polarimetric Backscatter (SAR)

EcoSAR can operate in single antenna and polarization transmit, single antenna dual polarization transmit, or dual antenna dual polarization transmit modes. Both polarizations on both antennas receive in all cases. In a 
single antenna dual polarization system, there are two transmit and two receive channels providing a total of four polarizations $(\mathrm{HH}, \mathrm{VH}, \mathrm{HV}, \mathrm{VV})$. EcoSAR has a total of four transmit and four receive channels, and generates a total of 16 different polarimetric backscatter images. For most of the 2014 flight campaign, left antenna vertical transmit was turned off, providing an opportunity to sample the RFI in all channels. A quad-polarization sample of the collected data is shown in Figure 2.

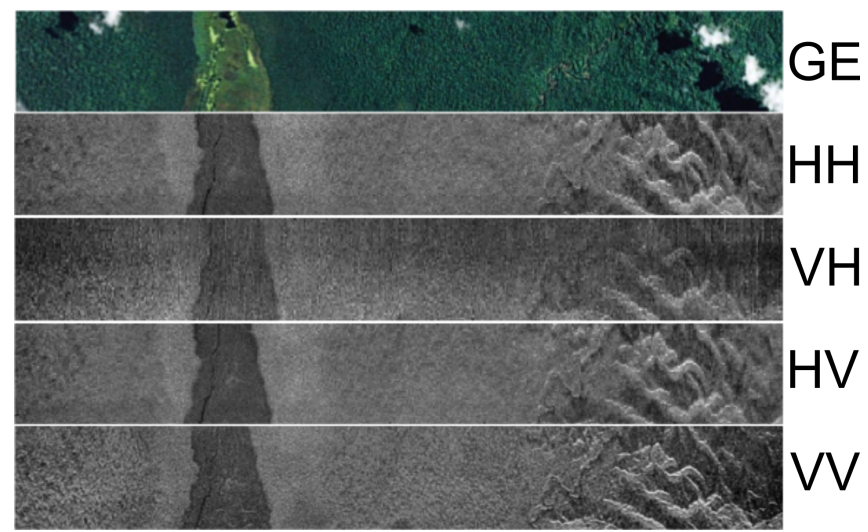

Figure 2 EcoSAR polarimetric measurements. GE: Google Earth, HH, VH, HV, and VV Polarizations.

\subsection{Phase center height (InSAR)}

EcoSAR antennas are mounted on the outer bomb racks of a P-3 providing a $25 \mathrm{~m}$ baseline. In case of dual-antenna transmit (ping-pong) mode the synthetic baseline is double the physical baseline, allowing for increased sensitivity to height measurements. Figure 3 presents a sample interferogram where each fringe corresponds to about $50 \mathrm{~m}$ relative height difference.

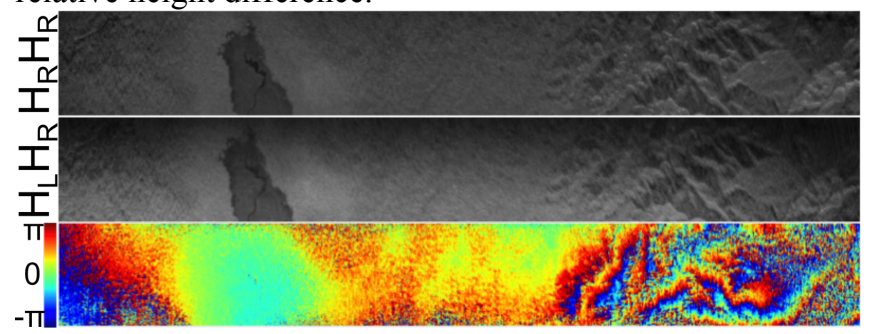

Figure 3 EcoSAR Single Pass Interferogram from a single (right) receiving antenna.

\subsection{Random Volume over Ground (PolInSAR)}

EcoSAR polarimetric backscatter images shown in Figure 2 can be further processed to estimate tree heights based on $\mathrm{RVoG}$ inversion. There were no corner reflectors available in the 2014 flight campaign complicating the radiometric calibration of each channel, and complete calibration of the data is still ongoing. However a Pauli image constructed from the data shown earlier reveals EcoSAR's polarimetric sensitivity to underlying forest structure (Figure 4).

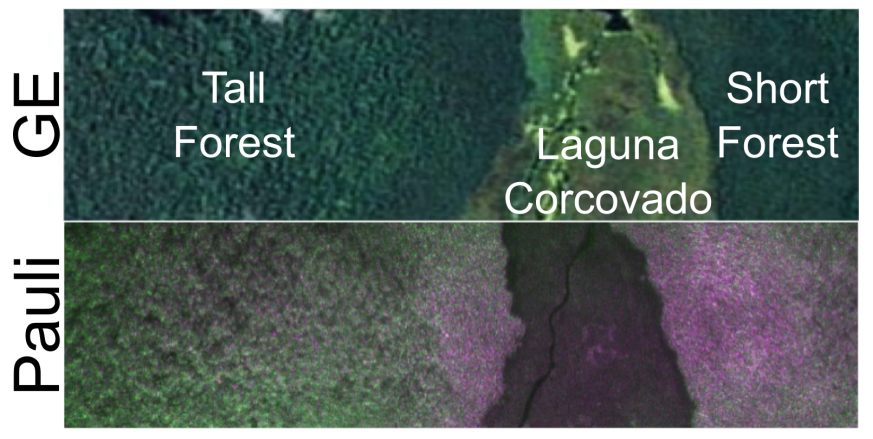

Figure 4 Pauli decomposition of EcoSAR data, corresponding to the underlying forest structure.

\section{CONCLUSIONS}

EcoSAR is a unique sensor with great capacity to map forest structure.

\section{REFERENCES}

[1] M. C. Dobson, F. T. Ulaby, T. LeToan, A. Beaudoin, E. S. Kasischke, and N. Christensen, "Dependence of Radar Backscatter on Coniferous Forest Biomass," Geosci. Remote Sens. IEEE Trans. On, vol. 30, no. 2, pp. 412-415, 1992.

[2] R. F. Rincon et al., "EcoSAR, An airborne P-band Polarimetric InSAR for the measurement of Ecosystem structure and biomass," in EUSAR 2014; 10th European Conference on Synthetic Aperture Radar, 2014, pp. 1-4.

[3] R. F. Rincon et al., "The EcoSAR P-band Synthetic Aperture Radar," presented at the 2011 IEEE International Geoscience and Remote Sensing Symposium, 2011.

[4] R. F. Rincon et al., "ECOSAR'S PERFORMANCE ASSESSMENT AND FIRST FLIGHT CAMPAIGN RESULTS," presented at the Geoscience and Remote Sensing Symposium (IGARSS), 2014.

[5] K. J. Ranson, S. Saatchi, and G. Sun, "Boreal forest ecosystem characterization with SIR-C/XSAR," IEEE Trans. Geosci. Remote Sens., vol. 33, no. 4, pp. 867-876, Jul. 1995.

[6] H. Balzter, "Forest mapping and monitoring with interferometric synthetic aperture radar (InSAR)," Prog. Phys. Geogr., vol. 25, no. 2, pp. 159-177, Jun. 2001.

[7] D. Liu, Y. Du, G. Sun, W.-Z. Yan, and B.-I. Wu, "Analysis of Insar Sensitivity to Forest Structure Based on Radar Scattering Model," Prog. Electromagn. Res., vol. 84, pp. 149-171, 2008.

[8] S. Saatchi, M. Marlier, R. L. Chazdon, D. B. Clark, and A. E. Russell, "Impact of spatial variability of tropical forest structure on radar estimation of aboveground biomass," Remote Sens. Environ., vol. 115, no. 11, pp. 2836-2849, 2011.

[9] S. R. Cloude and K. P. Papathanassiou, "Polarimetric SAR interferometry," Geosci. Remote Sens. IEEE Trans. On, vol. 36, no. 5, pp. 1551-1565, Sep. 1998.

[10] S. R. Cloude and D. Corr, "Tree-Height Retrieval Using Single Baseline Polarimetric Interferometry," in Proceedings of ESA Workshop, POLInSAR, 2003, pp. 1416. 